\title{
Erratum to: Characterization of Clinical Isolates of Gordonia Species in Japanese Clinical Samples During 1998-2008
}

\author{
Kazuki Aoyama · Yingqian Kang • \\ Katsukiyo Yazawa · Tohru Gonoi • \\ Katsuhiko Kamei · Yuzuru Mikami
}

Published online: 6 January 2010

(C) Springer Science+Business Media B.V. 2010

Erratum to: Mycopathologia (2009) 168:175-183 DOI 10.1007/s11046-009-9213-9

Unfortunately there is a small but important mistake in the final sentence of the third paragraph of the section entitled "Results and Discussion". The word "susceptible" should be replaced with "resistant", thus it should read as: "All strains were resistant to ST drug (sulfamethoxazole/trimethoprim)." 